\title{
Feminist Analysis of Pearl S. Buck's "House of Earth" Trilogy
}

\author{
Caiyuan Sun
}

School of International Education, Shandong Xiehe University, Jinan, Shandong, China

Keywords: Pearl S. Buck; House of Earth; feminist

\begin{abstract}
Pearl Buck's "The Land Trilogy" includes three parts: "House of Earth", "Son" and "Separation", as an important pioneer in advocating women's liberation. In these three works, the author portrays a variety of women. The image left a deep impression on the reader. It can be seen that the research on the female image in the Pearl S. Buck "House of Earth" trilogy has importantly practical significance.
\end{abstract}

\section{Introduction}

The current era is an era of rapid development of globalization. What people in this trend care about and think about is: What kind of new world should human beings build in the new century? How do people from different cultures communicate and how to get along with people in different cultures? It is in this way In the cultural context, it is very important to conduct serious research on the American female writer Pearl S. Buck, who is dedicated to the cultural exchanges between China and the United States, and his representative House of Earth.

\section{Female Image in Pearl S. Buck "House of Earth" Trilogy}

The opening story of House of Earth is a backward village in the early 20th century that was shrouded in old-fashioned social thoughts. In this era, Pearl S. Buck portrays a variety of traditional female characters in House of Earth, such as Alan, Pear, Lotus and Rhododendron. These female characters live at the bottom of society, and under the circumstance of patriarchal system, their own life value is difficult to be exerted. Combining the traditional concept of women in society at the time, the author divided them into two categories, one is a woman with traditional Chinese virtues, represented by Alan and Pear; the other is a woman who does not have traditional Chinese virtues, with lotus and rhododendron as the representative. Alan is a perfect interpretation of the traditional virtues of China. It is a female image portrayed in the Pearl S. Buck House of Earth Trilogy. Alan has a lot of fate. At a very young age, his parents who have been fleeing have been sold as a ring, and they have experienced long-term abuse in the rich. After Wang Longyu entered the house, he was bullied by his husband and was regarded as a tool for venting his desire and continuing the incense, but he did not receive the respect he deserved. After Alan gave birth to his son to Wang Long and his own aging, Wang Long put Alan all his efforts behind him, and he was able to bring a great blow to Alan's body and mind. This shows that Alan is portrayed by Pearl S. Buck, a Chinese traditional woman who lives in a patriarchal society and is bullied and trapped. Based on this, the author also added the spirit of the corresponding independent personality and doubtful traditional thought to Alan. Affected by the famine, the Wang Long family had to flee to the south. When I first entered the South, when my family was unable to do anything, Alan responded with her own calmness and took care of her family's life. With his extraordinary will and excellent ability, Alan provides a reliable guarantee for his family's life, so that the king can get rid of the predicament of life and embark on the road of making a fortune. This also reflects from another aspect that in the patriarchal society, even though Alan has not accepted the influence of new ideas, he has shown a certain independent and self-improving subject consciousness. Her wisdom above men and the behavior of participating in public life all reveal the possibility of women's liberation and clarify the feminist ideas of Pearl S. Buck. Ewha has a very similar life experience with Alan. The difference is that pear blossoms are swallowed up. Although it has Chinese traditional virtues, it lacks Alan's 
self-reliance spirit. For lotus and cuckoo, Pearl S. Buck portrays them as women who do not have the traditional virtues of China. Under the patriarchal society, they do not have the ability to live independently, they are eager to enjoy, and all luxury life depends entirely on men. They are both victims of patriarchal society and weak people in the patriarchal society. For Chinese women of that era, they did not serve Alan and Ewha with traditional Chinese virtues, or lotus and rhododendrons with Chinese traditional virtues. They all had the characteristics of "female" and did not have independent personality. It was the period of Chinese feudal decline. The old-fashioned female image that was born.

\section{Feminist Theory}

In the history of literary theory in the 20th century, feminist culture has an important position. Deconstructing the genres of Western literary theory after criticism, feminists are all involved, and some have become important forces. It is the result of the Western feminist movement rising and deepening into cultural and literary studies. At the same time, it is a strong rebellion against the traditional patriarchal centralization and patriarchal discourse, and has a strong political tendency. Feminist criticism mainly uses a female perspective to make a new interpretation of literary works, and discovers female cultural traditions different from male culture. Feminist criticism attaches importance to literary history and values other people 2 Women, paying attention to and promoting feminism Writing style. It can be said that it is not only the product of the feminist movement, but also the sharp weapon and important battlefield of the feminist movement. Feminist criticism played an important role in the 20th century Western literary theory from modern to postmodern, from knowledge discourse to political and ideology analysis, from poetic culture to cultural poetics, from the creation theory to the historical flood of criticism. In the post-modern cultural atmosphere, it shows prominent intermediary value functions in the development from deconstruction to neo-historicalism and post-colonialism. Of course, as a tradition that has been repeatedly subverted, feminist criticism is far from forming a truly consistent genre. Even in the form of genre, there are contradictions and ambiguities. However, it should be noted that feminist criticism has given a comprehensive and profound criticism of the patriarchal society and its values and literary views, and its criticism and research results have many new creations and developments, providing new research for the history of Western literature. From the perspective of excavation, many new materials have been discovered, and there have been many innovations in the method of theoretical explanation. They have made unique contributions in the history of history, the history of criticism, and the history of thought.

\section{Interpretation of "House of Earth"}

House of Earth is a novel by Pearl S. Buck in 1931 with the theme of China. It is a history of ordinary Chinese peasant Wang Long and his family who struggled and struggled to grow their land. The success of House of Earth is not only a vivid and realistic depiction of the peasants in Chinese society, but also a powerful attack on the masculine social concept of the time, enthusiasm for women's stubbornness and promotion of the then and later feminist rights. The development of the doctrine of movement. In the world at the time, especially in the East, women's status was low, they must be attached to men, oppressed by men and discriminated against. This reality has many manifestations in ideology. The first is the language issue. In the existing language system, men are always regarded as the only standard. Languages often have a tendency to devalue women. Some words related to women often have contempt, such as the use of the word mistr in the English hostess and mistress. Ess. The second aspect is the literary issue. In contemporary literary works, gender discrimination is very obvious. Female images are often divided into two extremes: good women and bad women. Even in Shakespeare's works, although women's images are vivid and unforgettable, female characters are divided. The tendency for the two poles has also not been avoided. Female writers have just begun to write novels and imitate the tendency of this bipolar classification. For example, the heroine Jane and the mad woman Baisha in Jane Eyre are 
representatives of good women and bad women. The third aspect is the creative environment of female writers, female artists and other talented women. The popular view at the time was that female writers should be as philanthropic as male writers. They must have a room they own. They must also have a passionate mood. It means that genius women cannot be like male geniuses in the past male days. Achievements. This view also indirectly shows that female genius has been discriminated against. British novelist and critic Virginia Woolf has done research and speculated that many young women who were burned to death as witches in the past are likely to be social rebellious or women with potential artistic genius. The publication of Pearl S. Buck's House of Earth is also a powerful refutation of the discriminatory view of women, which is manifested in the following two aspects: First, the award of House of Earth has improved the social status of female writers and female geniuses, and has despised the social atmosphere of women. It is a powerful irony. House of Earth won the Nobel Prize in Literature in 1938, and Pearl S. Buck became the first female writer to win the Nobel Prize in Literature in American history. The House of Earth has been translated into almost all the major texts in the world. It has been translated and published in more than 60 countries, and House of Earth has achieved great success. But at the same time, the awards also attracted the ridicule, dissatisfaction and even hostility of some male writers. The famous poet Robert Frauss once said: If she can win the Nobel Prize in Literature, then everyone should be no problem. 55 The famous novelist William Faulkner is more sarcastically saying that he is willing to not take the Nobel Prize for Literature, and he is not willing to join Pearl S. Buck. The reason why these writers criticized and criticized Pearl S. Buck for being difficult to put on the table is that she is a woman writer. Prior to this, only two male writers in the United States won the Nobel Prize in Literature. The award of Pearl S. Buck is a powerful maintenance of women's social status. It must cause a great imbalance in the mentality of men who have historically despised women's abilities and status. On the other hand, Pearl S. Buck's shaping of women in House of Earth is an affirmation of feminism. Pearl S. Buck is keenly aware that the most fundamental reason for the oppression of Chinese women, in addition to the class system, is the patriarchal system, which is the focus of her emphasis. The vast majority of women in the Pearl S. Buck lifestyle are at the bottom of society. The biography of Pearl S. Buck to his mother reflects the behavior of infanticide, foot-binding, and ignorance of women in Chinese society. But even in such a difficult environment, Chinese women have maintained a tenacious vitality and survived and struggled in the patriarchal system. Pearl S. Buck's insight into the patriarchal oppression was a pioneer at the time. 26 She sympathizes with the situation of Chinese women, admires her unyielding spirit, and truly reproduces their image through figures such as Alan in the House of Earth works. She is not limited to merely describing them as victims, but giving them a dominant position, proactively fighting against the patriarchal system, and actively seeking space for survival in a hostile environment.

\section{Comparison of Female Images in Pearl S. Buck’s “House of Earth” Trilogy}

From Alan to Melin, all of them have the best wishes of Pearl S. Buck for Chinese women. In The Land, Alan interprets the traditional Chinese image of women. They are not only victims of the patriarchal society, but also the weak of the old times. In "Son", Mrs. Wang Hu explained the female image of the old and new era in China. Under the influence of traditional ideas, they relied on men to earn a living on the one hand and accepted the influence of new ideas on the other. They not only have the virtues of traditional women, but also the wisdom of modern women. It is also because of their existence that the new era of women who were later represented by Mei Lin was born. In "Separation", Mei Lin interprets the female image of China's new era, and is also the female image advocated by Pearl S. Buck. They also have both external beauty and inner beauty, and they actively participate in the practice of equality between men and women and give back as much as they can. Society, to play its own life value.

\section{Conclusion}

House of Earth is regarded as a model for intercultural communication. In addition, the 
awakening of the female protagonist's consciousness in House of Earth is very clear, strong, and cannot be ignored. Pearl S. Buck pays attention to women and is always sensitive and sympathetic to the fate and suffering of women. In her works, women often appear as positive images. Pearl S. Buck communicates with millions of people in the United States and around the world through works represented by House of Earth. The feminist views in her book have been widely circulated in the society of the United States and many other countries. And is generally accepted. In the history of the development of women's thoughts, Pearl S. Buck has contributed, and House of Earth has contributed.

\section{References}

[1] Wang Yuzhi, Xie Danyan. The daughters of the earth - reviewing the female image of the Pearl S. Buck House of Earth trilogy [J]. Journal of Liaoning Administration College, 2008, 10 (11): 179-181.

[2] Dong Xiaotian. Contrast of Female World View in House of Earth -- On Alan, Pear and Lotus in Pearl S. Buck [J]. Grand View, 2014, (11): 162-163.

[3] Lei Pengcheng. A male epic written by a woman—-On the image of Chinese women in Pearl S. Buck House of Earth [J]. Journal of Shenyang University (Social Science Edition), 2007, 9(6): 5-7.

[4] Zhu Kun collar. Pearl S. Buck's View of Chinese Women-Feminist Interpretation of the House of Earth Trilogy [J]. Journal of Jiangsu University (Social Science Edition), 2003, 5(3): 69-73.

[5] Lu Mei. The fate of three generations of women in the House of Earth trilogy [J]. Journal of Kaifeng College of Education, 2016, 36(2): 58-60. 